\title{
Correction to: Co-producing Psychiatric Education with Service User Educators: a Collective Autobiographical Case Study of the Meaning, Ethics, and Importance of Payment
}

\author{
Sophie Soklaridis ${ }^{1} \cdot$ Alise de Bie ${ }^{3} \cdot$ Rachel Beth Cooper $^{2} \cdot$ Kim McCullough $^{4} \cdot$ Brenda McGovern $^{9} \cdot$ Michaela Beder $^{2,5}$. \\ Gail Bellissimo $^{10}$ - Tucker Gordon $^{1}$. Suze Berkhout ${ }^{2}$ - Mark Fefergrad ${ }^{6}$. Andrew Johnson ${ }^{1}$. Csilla Kalocsai ${ }^{1}$. \\ Sean Kidd ${ }^{1} \cdot$ Nancy McNaughton $^{7} \cdot$ Charlotte Ringsted $^{8} \cdot$ David Wiljer $^{7} \cdot$ Sacha Agrawal $^{1}$
}

(C) The Author(s) 2022

\section{Correction to: Academic Psychiatry (2020) 44:159-167 https://doi.org/10.1007/s40596-019-01160-5}

This article was updated to correct co-author Gail Bellissimo's last name.

Open Access This article is licensed under a Creative Commons Attribution 4.0 International License, which permits use, sharing, adaptation, distribution and reproduction in any medium or format, as long as you give appropriate credit to the original author(s) and the source, provide a link to the Creative Commons licence, and indicate if changes were made. The images or other third party material in this article are included in the article's Creative Commons licence, unless indicated otherwise in a credit line to the material. If material is not included in the article's Creative Commons licence and your intended use is not permitted by statutory regulation or exceeds the permitted use, you will need to obtain permission directly from the copyright holder. To view a copy of this licence, visit http://creativecommons.org/licenses/by/4.0/.

Publisher's Note Springer Nature remains neutral with regard to jurisdictional claims in published maps and institutional affiliations.
The online version of the original article can be found at https://doi.org/ 10.1007/s40596-019-01160-5

Sophie Soklaridis

sophie.soklaridis@camh.ca

The Centre for Addiction and Mental Health, Toronto, ON, Canada

2 University of Toronto, Toronto, ON, Canada

3 McMaster University, Hamilton, ON, Canada

4 Wilfred Laurier University, Waterloo, ON, Canada

5 Unity Health Toronto, Toronto, ON, Canada

6 Sunnybrook Health Sciences Centre, Toronto, ON, Canada

7 University Health Network, Toronto, ON, Canada

8 Aarhus University, Aarhus, Denmark

9 Toronto, ON, Canada

10 Mississauga, ON, Canada 